\title{
Parental involvement in the puerperal pregnancy cycle: experiences and feelings
}

\begin{abstract}
Objective: Describe the parents' perception of their fatherhood during pregnancy, childbirth and the puerperium.

Methods: it's a qualitative study, which the data were collected through a semistructured interview with 30 parents who had their children born in a public hospital. The thematic analysis followed Minayo's theoretical framework.

Results: it was identified that parental involvement is being more active nowadays, the involvement begins from the reception of the news of being a father, going through the expectations of what will be the characteristics of his son and the prenatal followup. The father becomes a participant in the actions of care for the companion and the child.

Conclusion: the study brought contributions to prenatal care and growth and development consultations, revealing the need to socialize the tendencies to provide assistance to the trinomial (mother-child).

Descriptors: paternity, parent-child relations, pregnancy, parturition, postpartum period
\end{abstract}

Volume 5 Issue I - 2018

Fernanda Letícia da Silva Campanati,'

Alayne Larissa Martins Pereira,' Casandra

Genoveva Rosales Martins Ponce de Leon,'

Laiane Medeiros Ribeiro,' Juliana Machado

Schardosim, ' Alecssandra de F Silva Viduedo,'

Danielle da Silva Fernandes, ${ }^{2}$ Géssica Borges

Vieira $^{2}$

'Departamento de Enfermagem, Universidade de Brasília (UnB), Brazil

${ }^{2}$ Programa de Pós- graduação de Enfermagem, Universidade de Brasília, Brazil

Correspondence: Casandra GRM Ponce de Leon,

Departamento de Enfermagem, Universidade de Brasília (UnB), Brazil, Email casandrapleon@gmail.com

Received: September 22, 2017 | Published: January 09, 2018
Abbreviations: IRAMUTEQ, interface for multidimensional analyzes of texts and questionnaires; CHD, descending hierarchical classification

\section{Introduction}

The involvement of the father is much more intricate than it appears to be, three initial phases are of great relevance in the change that occurs both in the life of the man and in the life of the woman. In the first phase, which corresponds to the gestation of the woman, the main changes are related to the initial feeling of paternity and the preparation for the arrival of the child. The second phase, which includes childbirth, whether or not the father's participation at this moment directly influences the formation of the first paternal bond with the child, and where emotional support also occurs for the woman who goes through labor and delivery. And it is in the puerperium, the third and last phase, that the whole family routine changes and the bond is concretely formed, and usually most doubts about the child and its future arise. ${ }^{1}$

The traditional model of care must be rethought in order to incorporate the presence of the father, so that it may have an easy access to health services. ${ }^{2}$ Parental care and support for women during the puerperal pregnancy cycle were not usually treated as essential to the care of the female partner. In view of this, it is worth mentioning that the purpose of the Stork Network is to guarantee the woman an accompanying person during the reception and labor, delivery and immediate postpartum, thus indicating the importance of the support that the man/father has in this scenario. ${ }^{3}$ It is important to note that Law no. 11,108 of 2005 provides women with the right to choose to have a companion in labor, delivery and immediate postpartum in Brazilian health institutions, whether public or private. ${ }^{4}$ Often, neglect in this item, compromises the support that the pregnant woman expects at the time of delivery.
Parental involvement during the phases of the puerperal pregnancy cycle has several positive effects on child development, thus contributing to a greater social competence and capacity for emotional regulation of the children in the future. In addition, authors affirm that, this paternal involvement can contribute also helping to moderate the effects of depression and non-maternal responsiveness in the puerperium. ${ }^{5}$ Therefore, this study aims to describe the perception of parents about their fatherhood during gestation, childbirth and the puerperium.

\section{Methods}

This is a qualitative research, using thematic analysis, ${ }^{6}$ performed in the joint housing of a public hospital of the Federal District from March to August 2015. Data collection was through an interview recorded on a digital device and transcribed in full with a structured script. The interviews took place in a reserved room inside the maternity ward, to ensure the parents' privacies, with an average duration of 25 minutes. The thematic analysis aims to identify the nuclei of meaning that are part of the observed communication, whose presence or frequency is significant for the research and brings a bundle of relations that can be evidenced by a word, phrase or a summary. The thematic analysis involves a pre-analysis, followed by the floating reading of the interviews in search of the central ideas in the speeches. At that moment the corpus was created, grouping the interviews by their common characteristics, being the corpus of convergent or divergent nature. Then the corpus was submitted to a text clipping in registration units, formed by phrase, word, excerpt or theme that allowed a more detailed comparison. ${ }^{7}$ Finally the answers were compared with the current literature and the men's/parents' points of view were analyzed.

The interviewer was a graduate student trained to conduct interviews. The convenience sample included 30 parents. Inclusion 
criteria were: age equal or superior to 18 years and accept to participate in the research. The parents were coded as follows: P1 to P30, where P refers to the Interviewee and the Arabic numerals from 1 to 30 refer to the order of interviews. Also, the IRAMUTEQ (Interface of Multidimensional Analyzes of Textes et de Questionnaires) for the word cloud and the Descending Hierarchical Classification (CHD) method $^{8}$ was used in the data analysis. It is emphasized that the use of software is not a method of data analysis, but a tool to process them, so the interpretation of data is the responsibility of the researcher. The study respected the formal requirements contained in the national and international norms regulating research involving human beings.

\section{Results}

The results are organized in two ways: the first, by the word cloud method and the second by the Descending Hierarchical Classification (CHD) method, highlighting the thematic categories that emerged in the analysis of interview data. Using the word cloud method, which groups the words and organizes them graphically according to their frequency, the word ESTAR was the one that had the highest frequency in the corpus 202 times, followed by the word HELP, 125 times (Figure 1 \& Figuire 2).

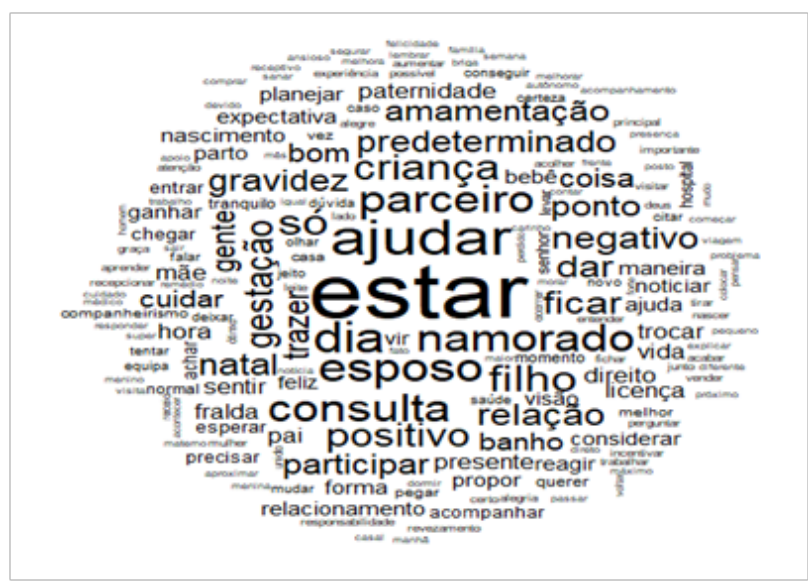

Figure I Word cloud organized by IRAMUTEQ software.

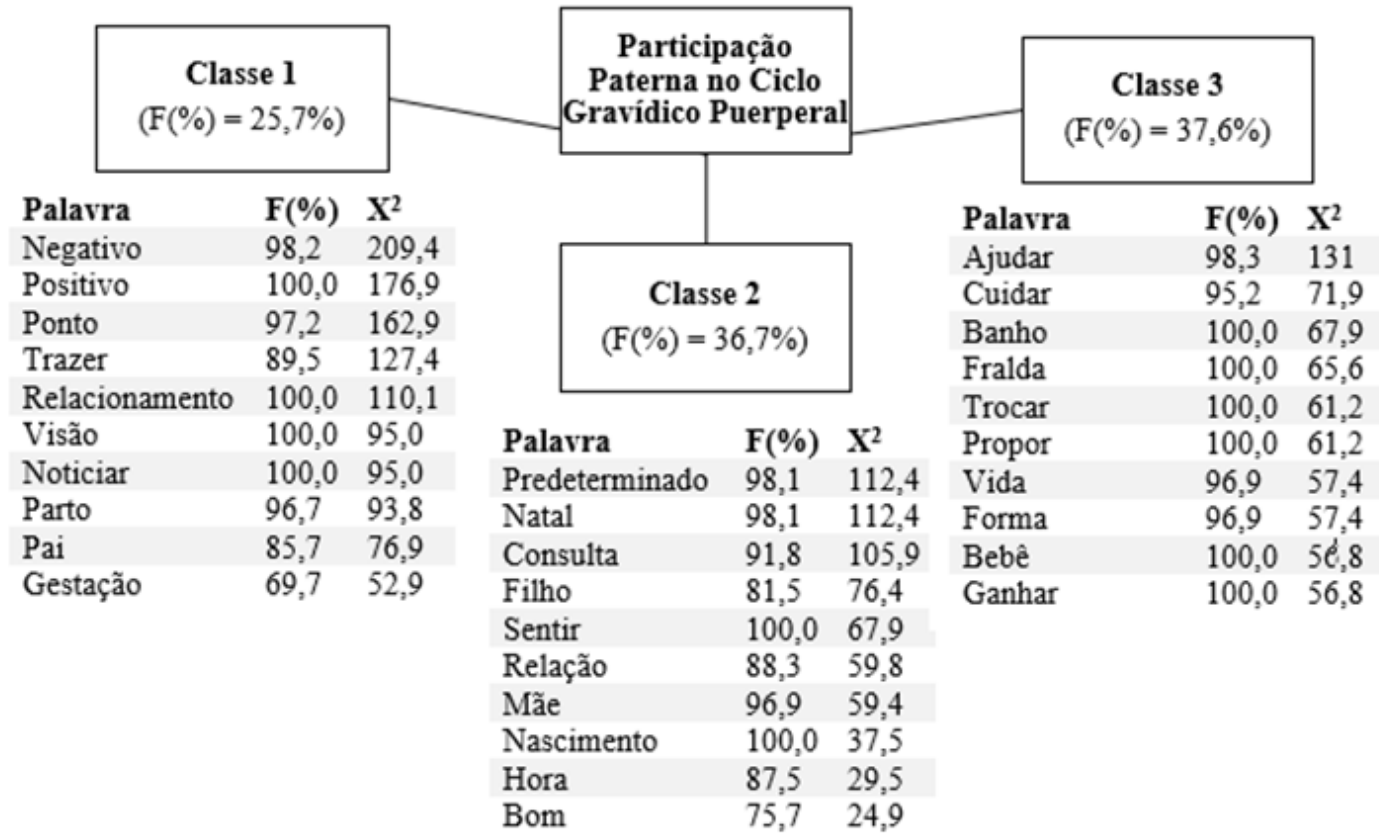

Figure 2 Dendogram and lexical classes on paternal participation in the pregnancy-puerperal cycle.

Category I: vision of the father about the news of gestation: positive and negative points

This category describes the feelings and expectations that the participants reported to have arisen on the news of being a parent. Oh, I was very happy, I waited, my biggest expectation was that she was born on the day of my birthday (Father 02), another father mentions about the surprise of the gestation, after four months I learned, she came to me and said: I was pregnant, my reaction was very strong, I was shocked, I was very happy (Father 19) and still on the question of life change, in the beginning it was a bit, it was a thud, then it was normal. To form a family, to change one's life, that has completely changed and joy is to be a father (Father 26).

Another point is the concern of parents about the possibility of something wrong or something that was not foreseen during pregnancy, such as abortion, prematurity, which may be associated with previous experiences, expected that it would be born with normal gestation that it was born premature, that was the only bad thing (Father 15). In relation to the positive and negative points, parents report that the relationship increased affection and love that is a positive point, had no negative point no (Father 28). When asked if the news of being a father had added positive points to the relationship with his partner, we obtained the following answers: for me another daughter only brought more positivity, both for me and for my wife, gave a renewed still, it can be said (Father 04). Another parent mentioned that anxiety is a downside but companionship has increased a lot (Father 29).

\section{Category 2: relation with the mother of your child, feelings in the prenatal visit and at birth}

This category describes how the process of father's participation in the follow-up of the prenatal care of his companion and son takes place, he tried to be more participative, he asked, he asked the doubts. 
He was watching, see if there was nothing wrong with the child (Father 03); Every time I went in with her, I even got my doubts. I was very comfortable, every doubt I had I asked and they answered me with clarity, it made me understand everything (Father 15).

In cases where the father is present in the consultation, delivery and postpartum, he has shown a positive attitude towards the development of the self-image of fatherhood, as we can see in the following reports: If he feels important, because the presence of the father is important at all times pregnancy (Father 19). First they began to show me the little parts of him, the heart, we are very happy with the beating of his heart, when he also showed us what sex was, we are very satisfied (Father 12). On the other hand, it is observed that the man wishes to get involved in the pregnancy-puerperal period, but some complained about the lack of reception. ${ }^{9}$ That was sad at the post unfortunately, at the time of asking, it was all a question for Mom (Father 24). Other lines that help us understand the whole context, I never entered, but I always went with her at the post, but I never went in, I was just outside. More who went with her was always me (Father 05), encourage not encouraged not, but welcomed me super well (Father 15).

\section{Category 3: participation of the father in the daily care with the baby}

This category aims to demonstrate how parents are proposing to help and to participate more actively, both in caring for their partner and in caring for their child. They still understand that the role of the father is that of provider, and they list the financial part, the costing of goods, both for the mother and the child, as an aid, In my view I totally dedicated myself to the gestation, paying consultation, (12), helping, taking care of the child, helping to buy things for him, because at the moment she will not be able to work (Father 05). Some companions may distance themselves from the paternal condition and value only the financial part, others seek to redefine social roles by becoming a participant in family life, participate, one does an hour, the other does another time, more do everything, change diapers (Father 12), look, I've already arranged with my wife, make a small relay, and when it's necessary for the night, Dad will be available and she needs to sleep, rest (Father 24). In some speeches parents are determined to make themselves present in the life of the woman and the baby, look first is presence, then my presence here is as possible, I am in the direct moment, I left service, I left everything to be present, this is the main fact that I am here, I think otherwise is more attention, right, and I am giving this attention (Father 24).

\section{Discussion}

The data demonstrated that paternal participation in the puerperal pregnancy cycle has become more active in the present day. Although prenatal care is the ideal time to prepare for this new phase of life, it can be seen that parental involvement is still resistant among health professionals, who did not include the paternal figure in the puerperal pregnancy process, limiting participation and the implementation in this new phase.

Faced with the statements of the interviewees, it is noticed that the parents feel the right to participate in the pregnancy-puerperal process, and emphasize the importance of the paternal presence, to clarify the doubts and desires that arise during this process. Anxiety, fear, anguish, idealization of the child's characteristics and a series of expectations are added to the emotional process of the parents interviewed, highlighting the interest and approximation that reveals a real experience of the parents in the pregnancy process that deserves consideration and reflection by the parents. Health professionals. A multi-center cohort study ${ }^{10}$ performed with parents of very low birth weight infants shows the relationship of postpartum depression in the parents of these preterm infants. This reinforces the need for health professionals to always include the father in prenatal consultations in order to raise the awareness of the father about the prevention of infections during pregnancy, the risks of premature birth, among other information relevant to parents in this phase of the pregnancy. puerperal pregnancy. With the discovery of pregnancy, the man can manifest ambivalent and contradictory feelings, and these can be due to several factors, ${ }^{11}$ among them the changes that occurred with his partner, the anxieties regarding the new role in society, responsibilities, among others. ${ }^{12}$ Feelings such as anxiety, worry, fear, nervousness and insecurity as exhibited in some of the above statements may be part of the man's experience in the puerperal gravid cycle, but these same feelings are being attenuated during gestation, ${ }^{13}$ as seen in class 1 of this study.

A randomized controlled trial conducted with couples aimed to examine the feasibility of improving the functioning of the marital relationship during the transition to paternity through the development and delivery of a low-intensity prenatal intervention, with the participation of 47 participants in the intervention group and 36 participants in the control group. The intervention of the study was a two-hour psycho-pedagogical program, initially tested in the United Kingdom, promoted by the National Health System, applied in prenatal consultations. As results were evaluated in terms of relationship satisfaction, communication between the couple and psychological distress. The intervention seemed feasible in terms of pragmatic delivery, acceptance rates, and participation in the sessions. The forms indicated that people were reasonably satisfied with the intervention and would recommend to friends. ${ }^{14}$ Health professionals should value the participation of the father in all phases of the puerperal pregnancy cycle, starting in prenatal care as shown by the importance in the study cited. An integrative review with the objective of analyzing the scientific production on the role of the man as companion in the parturition process of his companion selected 26 articles, and found that the presence of the partner in the parturition process was considered active when the latter developed activities considered satisfactory, such as emotional support to the partner at the time of contractions, by the researchers of the selected articles, concerning the development of actions that generated encouragement and support to the partner. In addition, the active presence of man was considered when the subject felt part of the process and exercised his role of companion and father. ${ }^{2}$ A study ${ }^{15}$ that had as objective to problematize three actions developed in basic health units of three municipalities of different Brazilian regions, focused on human health, the promotion of participative paternity and sexual and reproductive health. This is a qualitative research, by observations and interviews with 17 men, users of the health system and involved in these actions. In the analysis of the data, the concepts of gender, masculinities and Integrality were brought in. The authors concluded that men perceive that gender issues still impede this insertion, as well as the organization of the health system itself; and that the actions analyzed are organized in a sealed and fragmented way, acting on isolated aspects of male health, not contemplating the principle of integrality and making it difficult to promote the attachment of these men to the system for primary care. Another research evidenced that the father carries many doubts, because the lack of understanding about some phenomena characteristic of the pregnancy, mainly on the physiological bases of 
the appearance of different organic signs and symptoms, about the gestation and the development of the baby, with this, we understand that prenatal care is the opportune moment where doubts are healed. ${ }^{16}$ All the changes that begin to occur within the family are capable of generating feelings, anxieties and fears, these must be worked during the consultations, thus providing a quality care service and preparing the family in a safe and healthy way for the childbirth and postpartum. However, it is important to remember that the intensity of the involvement with prenatal care is unique, thus allowing each man to exercise his participation according to his personality ${ }^{17}$ as evidenced in class 2 of this study. A study ${ }^{18}$ that examined the changes that occur for the first time in the lives of couples who are going to have a child. The focus was marital quality of life during the transition to paternity as predictors of their co-parenting quality and involvement of parents with relatives and support for their co-parenting. Participants included 96 couples and were measured separately for "marital conflict" and "prenatal satisfaction" at 8 months and 24 months. The authors confirm that increases in conflict and decreased marital satisfaction that often coincide with the transition to parenthood have real implications for the degree to which each parent supports parenting and their level of involvement in parenting. A research ${ }^{19}$ that aimed to analyze how the father involvement occurs during the first three months of life, emphasizes that parents participated in the baby's life in an eventual or routine way, in the diaper change, in the bath, in the bottle, among others, argue that parents are becoming active participants and participants in both "nasty" moments such as changing diapers, vaccinations, meals, punishments and establishing limits, as well as in "pleasant" situations and games. In addition, the research cited reveals that being a present father implies sharing with the mother the basic care of the child, that is, the activities should be equally shared between both, causing both the man and the woman to provide care and energy in the care of the child, in the same amount of time. ${ }^{10}$ Results similar to our study, according to class 3 .

A study ${ }^{20}$ of exploratory and descriptive design, with method of qualitative data analysis, was carried out through content analysis. Four couples/parents of double work, aged between 26 and 40 years, answered a questionnaire on sociodemographic data and a semistructured interview on co-parenting. The results indicated that during the transition to parenting, the parents retain more of their personal space, while the parents feel overwhelmed by being held accountable for all the demands that involve this period.

Co-parenting is described as being developed in a more egalitarian way, since the early schooling of children and double work impose this dynamic. On the other hand, domestic tasks are still not divided equally, these being associated with gender roles. The results allowed an approximation with the reality of these couples, which indicated signs of changes in the performance of their co-parenting..$^{20} \mathrm{Up}$ to the present moment, some studies have reflected on the satisfaction of the father in the participation in the puerperal pregnancy cycle, but these studies highlight their limitations, such as: they only had the participation of the men, and I would like to know the opinion of the women in this participation of the in the puerperal gravid cycle, ${ }^{18}$ or the pilot study that evaluated the intervention (focal group with couples in order to normalize adverse changes reported by several couples in marital role functionality). ${ }^{14}$ This study emphasizes the role of health professionals in prenatal care and provides preliminary support for the feasibility, acceptability, and effectiveness of low intensity prenatal intervention in helping couples against the common stressors of becoming parents. Further large-scale research is needed to determine whether these encouraging preliminary results can be replicated.${ }^{14}$ One limitation in the use of the methodology chosen in the present study was the fact that the participants of the research expressed little in their answers, which limited the results. Despite the brief answers and the small number of participants (sample for convenience), we believe that the data collected can describe how the man / father participates in the puerperal pregnancy cycle (during gestation, delivery and puerperium) and point to the need of future research, which may include health professionals, in order to know their perception of including the father in pre-delivery, delivery and postpartum care; as well as identify which strategies are used in practice by health professionals to include the father in all stages of the puerperal pregnancy cycle.

\section{Conclusion}

Parents' participation and follow-up in prenatal care is necessary, demonstrating that the role of the male /father is only that of the provider and assumes a new position of participation in the process, that is, it is a time for learning, clarifying doubts and which in a way contributes to the realization of the child. Another situation that should be highlighted is the encouragement by health professionals to these parents, so that they actively participate in the prenatal consultation and that they have space for dialogue to clarify doubts about the pregnancy-puerperal cycle. Nevertheless, the present study demonstrates that paternal participation still deserves a great prominence in the scenario that starts from basic care until delivery in the hospital unit, allowing health professionals to include this figure in the pregnancy-puerperal process.

\section{Collaborations}

Campanati FLS and Pereira ALM, contributed in the conception, collection, organization and interpretation of the data. Ponce de Leon CGRM and Ribeiro LM contributed in the design, writing and critical analysis of the content, and together with Schardosim JM, Viduedo AFS, Fernandes DS and Vieira GB contributed in the final writing of the article and final approval of the version to be published.

\section{Acknowledgements}

None.

\section{Conflict of interest}

The auhtor declares no conflicts of interest.

\section{References}

1. Barbosa Jardim DM, Mattos Penna CM. Father-Escorts and their understanding about the process of birth of the child. REME Rev Min Enferm. 2012;16(3):373-381.

2. Ferreira IS, Carvalho Fernandes AF, Ricarte Lô KK, et al. Perceptions of pregnant women about the performance of partners in prenatal consultations. Rev Rene. 2016;17(3):318-323.

3. Martinelli KG, Santos Neto ET, Nogueira da Gama SG, et al. Adequacy of the process of prenatal care according to the criteria of the Prenatal and Birth Humanization Program and Stork Network. Rev Bras Ginecol Obstet. 2014;36(2):56-64.

4. Frutuoso LD, Bruggemann OM. Conhecimento sobre a lei 11.108/2005 e as experiências dos acompanhantes junto à mulher no centro obstétrico. Texto Contexto Enferm. 2013;22(4):909-917.

5. Santos SC, Kreutz CM. O envolvimento do pai na gestação do primeiro filho. Pensando Fam. 2014;18(2):62-76. 
6. Magalhaes Bosi ML. Desafios atuais para a pesquisa qualitativa: Considerações no cenário da saúde coletiva brasileira. Fórum Sociológico. 2014;24(1):1-12.

7. Camara RF. Análise de Conteúdo: da teoria à prática em pesquisas sociais aplicadas as organizações. Gerais. 2013;6(2):179-191.

8. Camargo BV, Justo AM. IRAMUTEQ: um software gratuito para análise de dados textuais. Temas Psicol. 2013;21(2):513-518

9. Almico T, Faro A. Enfrentamento de cuidadores de crianças com câncer em processo de quimioterapia. Psicol Saúde Doenças. 2014;15(3):723737

10. Helle N, Barkmann C, Bartz-Seel J, et al. Very low birth-weight as a risk factor for postpartum depression four to six weeks postbirth in mothers and fathers: Cross-sectional results from a controlled multicentre cohort study. J Affect Disord. 2015;180:154-161.

11. Ribeiro JP, Gomes GC, Silva BT, et. al. Participação do pai na gestação, parto e puerpério: Refletindo as interfaces da assistência de enfermagem. Espac. Saude. 2015;16(3):73-82.

12. Mota Zampieri MF, Guesser JC, Buendgens BB, et al. O significado de ser pai na ótica de casais grávidos: limitações e facilidades. Rev Eletrônica Enferm. 2012;14(3):483-493.

13. Souza D, Pinto RC, Gisolfi TT. Um pai que espera: Experiências de pais em relação a gestação de seus filhos. Rev Cien Inov. 2015;(1):1-37.
14. Daley-McCoy C, Rogers M, Slade P. Enhancing relationship functioning during the transition to parenthood: a cluster-randomised controlled trial. Arch Womens Ment Health. 2015;18(5):681-692.

15. Ribeiro CR, Gomes R, Moreira MCN. Encontros e desencontros entre a saúde do homem, a promoção da paternidade participativa e a saúde sexual e reprodutiva na atenção básica. Physis Rev Saúde Coletiva. 2017;27(1):41-60

16. Antunes JT, Pereira LB, Vieira MA, et al. Presença paterna na sala de parto: Expectativas, sentimentos e significados durante o nascimento Rev Enferm UFSM. 2014;4(3):536-545.

17. Henz GS, Medeiros CRG, Salvadori M. A inclusão paterna durante o prénatal. Rev Enferm Atenção Saúde. 2017;6(1):52-66.

18. Christopher C, Umemura T, Mann T, et al. Marital quality over the transition to parenthood as a predictor of coparenting. J Child Fam Stud. 2015;24(12):3636-3651.

19. Piccinini CA, Silva MR, Goncalves TR, et al. Envolvimento paterno aos três meses de vida do bebê. Psicol Teor Pesqui. 2012;28(3):303-314.

20. Pasinato L, Mosmann CP. The transition to parenting and coparenting: Couples that children were enrolled in school on the espiration of maternity leave. Avances en psicología latinoamericana, Bogotá. 2016;34(1):129-142. 